\title{
Empirical Analysis of Cost Estimation Accuracy in Procurement
} Auctions

\author{
Timothy D. Fry ${ }^{1}$, Robert A. Leitch ${ }^{1}$, Patrick R. Philipoom ${ }^{1} \&$ Yu Tian ${ }^{1}$ \\ ${ }^{1}$ Gambel Oak CT., USA \\ Correspondence: Yu Tian, Gambel Oak CT., USA. E-mail: yu.tian@ucf.edu
}

Received: December 19, 2015

Accepted: February 16, $2016 \quad$ Online Published: February 25, 2016

doi:10.5539/ijbm.v11n3p1

URL: http://dx.doi.org/10.5539/ijbm.v11n3p1

\begin{abstract}
This paper explores the impact of better cost estimation accuracy for a firm that bids on projects. Specifically, we investigate the effect of cost estimation accuracy on firms' ability to submit lower bids amounts and their likelihood of winning in a bidding environment. We analyze highway construction bidding data between year 2001 and 2009 from a state department of transportation. Our results suggest that firms with more accurate cost estimation are more likely to lower their bids amounts and thus are more likely to win more bids than firms that have less cost estimation accuracy. The findings help us better understand the process and effect of cost estimation accuracy in the bidding environment and provide practical implications.
\end{abstract}

Keywords: cost estimation, accuracy, bid amount, winning, bidding process

\section{Introduction}

Cost estimates are used by companies to make many operational and strategic decisions (e.g., Heitger, 2007; Ittner et al., 2002; Kaplan \& Norton, 2001). It is a reasonable conjecture that a company that can estimate its costs more accurately than its competitors should enjoy a competitive advantage in the marketplace. These advantages may include the ability to price their products lower than competitors and thus win more orders. More accurate cost estimation can be achieved through a variety of approaches. These approaches include, for instance, a better cost management system like activity-based costing, a more formal and deliberate cost estimation system, and/or the acquisition of additional supplementary information regarding the project (e.g., Anderson, 1995; De Silva et al., 2008; Gupta \& King, 1997; Ittner et al., 2002). However, as there is little evidence in the literature that more accurate cost estimates will necessarily lead to improvements in decisions or overall profits, several researchers have encouraged future studies to examine this relationship (Cooper \& Kaplan, 1991; Callahan \& Gabriel, 1998; Gupta \& King, 1997; Heitger, 2007; Swenson, 1995).

In order to increase our understanding of the relationship between better cost estimates and improvement in decisions, we investigate the effects of cost estimation in a reverse auction setting (Note 1) using a large sample of data between year 2001 and 2009 from a state Department of Transportation (DOT) for publicly funded highway construction projects. The data includes 6,558 projects that were open to any company wishing to bid on the project. For each project, a set of companies submit bids to the DOT who then, in a public forum, open the sealed bids and award the contract to the lowest bidder. There are many other examples of companies that routinely participate in a reverse auction. For example, professional firms (e.g., accounting firms) bid on engagements, contractors bid on public and private construction projects, oil and gas companies bid on tracts for drilling rights, and businesses bid on procurement contracts to supply governmental agencies or other business. To measure cost estimation accuracy, we use standard deviation of bid's percent difference from the median bid as a proxy for cost measurement error. Our results suggest that on average, firms with more accurate cost estimates are able to lower their bids amounts and thus tend to win more bids than firms that have less cost estimation accuracy.

This study has important implications and contributions. First, despite the importance of cost estimate accuracy for many operational decisions, there is little empirical evidence that more accurate cost estimation leads to improvements in managerial decisions and competitiveness (e.g., Cooper \& Kaplan, 1991; Gupta \& King, 1997; Heitger, 2007; Swenson, 1995). Using bidding data from the highway construction industry, this paper contributes to our understanding of the importance of cost estimation accuracy in the bidding process. In particular, this study shows the importance of cost estimation on the ability of a company to submit lower bids 
and increase their likelihood of winning a project.

Second, this study has important practical implications for any company that routinely competes in reverse auctions. In the highway construction industry, many companies may not have an obvious cost advantage because they generally draw from the same labor pool, use the same suppliers, and use similar equipment. Therefore, estimating costs more accurately will reduce uncertainties associated with estimation errors thus allowing the company to reduce its price. Lastly, this study sheds light on prior research by using different research methodologies. Prior research in this area are mostly theoretical or/and experimental work (e.g., Callahan \& Gabriel, 1998; Gupta \& King, 1997; Heitger, 2007), while our study utilizes a large sample of empirical data from practice and provide evidence about the effect of better cost estimation in the bidding process.

The remainder of the paper is organized as follows. We review prior literature and develop our hypotheses in Section II. Section III describes our sample and variables, and presents our results of the hypotheses. Concluding remarks are offered in Section IV.

\section{Literature Review and Hypotheses}

Many studies in accounting literature emphasizes the importance of cost estimation accuracy, suggesting that accurate cost estimates are important inputs into numerous strategic and other managerial operational decisions (Anderson, 1995; Kaplan \& Cooper, 1998; Heitger, 2007; Ittner et al., 2002; Kaplan \& Norton, 2001). Gupta and King (1997) investigate the ability of a decision maker to learn from feedback in an experimental setting and make effective decisions even with imperfect cost reports. They find that, when participants learned from the feedback and updated their cost estimates making reports more accurate, profits increased. However, instead of directly testing the linkage between cost estimation accuracy and firms' profits, prior studies generally assume that more accurate cost estimates would necessarily lead to increased profits (e.g., Babad \& Balachandran, 1993). In addition, there is also a lack of research as to whether cost estimation accuracy leads to improvement in other managerial decisions as we do in this study.

Callahan and Gabriel (1998) examine the impact of accurate product cost information on firm profits in an imperfect market setting and suggest that the value of more accurate cost information may be dependent on the firm's competitive market structure. In a manner similar to Datar and Gupta (1994) and Christensen and Demski (1995), Callahan and Gabriel (1998) define cost estimation error as the variance of the cost report where those with low variance are considered more accurate. Using theoretical analysis, Callahan and Gabriel (1998) show that firms that compete on the basis of cost leadership (which may be characterized as a Cournot competition) will realize increased profits from more accurate cost estimates. However, firms that compete on the basis of product differentiation (operationalized as Bertrand competition), may not benefit from better product cost estimates.

Despite the importance of cost estimation accuracy acknowledged by prior research, there is little empirical evidence that more accurate cost estimation leads to improvements in decisions or overall competitiveness. Further, there is limited consensus among researchers about this linkage (Callahan \& Gabriel, 1998; Gupta \& King, 1997; Heitger, 2007). Prior studies encourage future research on whether accuracy of cost system could improve decisions, cost management and control, strategy formulation, and strategic management in organization (Gupta \& King, 1997). This paper contributes to this area in understanding the importance of cost estimation accuracy to company's competitiveness. Specifically, we extend prior research by using empirical bidding data from the highway construction industry to explore the importance of accurate cost estimation in a procurement auction on the likelihood of submitting lower bids and likelihood of winning more bids. These two abilities are important in the bidding environment for to be profitable, a company must be able to submit bids that are low enough to be competitive yet high enough to mitigate the impacts associated with the winner's curse.

In this study, we use the median of all companies' bids for a particular project as a benchmark to measure the accuracy of cost estimates, as the median represents a consensus of project value (we will discuss this in details in the next section). The bid amount submitted by a company will include a markup added to the project cost estimate to account for desired profit as well as any informational uncertainties, i.e., cost estimation errors. Surveys (Gordon et al., 1981; Govindarajan \& Anthony, 1983) as well as anecdotal evidence suggest that cost information is widely used to set prices, because costs can be reasonable surrogates for marginal costs upon which prices should be set based on expected utility theory (Hilton et al., 1988). We argue that companies that have more accurate cost estimation procedures (i.e., distributions closer to the median bidding value), for whatever reason, will submit lower bids. This is possible since the uncertainty surrounding the cost estimate is 
reduced thus any markups applied to a cost estimate doesn't have to compensate for this uncertainty (Hilton et al., 1988). At the same time, there will be a lower probability for these companies to lose money on a project compared to their competitors. That is, they will be less likely to experience the winner's curse. Therefore, if companies can estimate the cost of a project more accurately, they will tend to lower their bids amounts in order to win the project. This leads to our first hypothesis:

Hypothesis 1: A better cost estimation accuracy (i.e., a tighter bid distribution around consensus values like median) will lead to lower bids amounts on average.

Our second hypothesis looks at the effect of company size on their bids amounts. We argue that larger companies usually have more expertise and experience in the bidding process as well as cost estimation resources, such as a larger group of engineering staffs, and thus have an advantage in bidding. That is, a lot of bids are based on historical bidding activities as well as knowing their competition. Here the competition is broad based - there are many companies in the business (367 firms in our dataset). Therefore, larger companies may tend to have better processes for cost estimation, that is, their bids amounts are more likely to be close to the consensus values. Therefore, we predict that:

Hypothesis 2: A larger company will tend to have better cost estimation accuracy than a smaller company (i.e., a tighter bid distribution around consensus values like the median).

In addition, we investigate characteristics of companies that win bids compared to those that do not. A company can increase the probability of winning more bids just by bidding consistently low. However, in this case, they will be more likely to experience the winner's curse thus being less competitive in the market. Alternatively, if a company can estimate its costs more accurately, as indicated by a tighter bid distribution around the median, they may be able to bid lower with less concern of winning unprofitable bids, because they have more accurate estimates of costs than their competitors. Thus companies with more accurate cost estimation should win a higher proportion of the projects on which they bid, compared to those companies with less accurate cost estimation. This leads to our third hypothesis:

Hypothesis 3: A company with better cost estimates (i.e., a tighter bid distribution around consensus values like median) will win more bids than a company with less accurate cost estimates.

\section{Empirical Data and Results}

\subsection{Empirical Data}

We collected the bidding data for highway construction contracts (between year 2001 and year 2009) from a state Department of Transportation website. Only projects which had four or more competing bids were included in our sample. Our sample is comprised of 6,558 usable projects that had bids submitted by 367 different companies. Table 1 presents some descriptive statistics for our sample. Panel A of Table 1 provides the frequency of bids amounts for different ranges. There are 382 bid observations (5.82\% of the entire sample) that are more than $\$ 10$ million, 802 bid observations (12.22\% of the sample) that are more than $\$ 5$ million, 2791 bid observations ( $42.56 \%$ of the sample) that are more than $\$ 1$ million, and 5356 bid observations $(81.67 \%$ of the sample) that are more than $\$ 250,000$. We also present the number of bids by firm in Panel B of Table 1 . There are 19 companies that bid more than 100 projects, accounting for $5.18 \%$ of the sample. There are 116 companies that bid more than 10 projects, accounting for $31.61 \%$ of the sample.

Table 1. Descriptive data

\begin{tabular}{lll}
\hline Panel A: Frequency of Bids Amounts & & \\
\hline Bids Amounts Range & $\begin{array}{l}\text { Number } \\
\text { Amounts }\end{array}$ & Bids \\
\hline More than $\$ 10$ million & 382 & $5.82 \%$ \\
More than 7.5 million but less than \$10 million & 160 & $2.44 \%$ \\
More than 5 million but less than 7.5 million & 260 & $3.96 \%$ \\
More than 2.5 million but less than 5 million & 627 & $9.56 \%$ \\
More than 1 million but less than 2.5 million & 1362 & $20.77 \%$ \\
More than \$750,000 but less than \$1 million & 577 & $8.80 \%$ \\
More than $\$ 500,000$ but less than \$750,000 & 635 & $9.68 \%$ \\
\hline
\end{tabular}




\begin{tabular}{lll}
\hline More than $\$ 250,000$ but less than $\$ 500,000$ & 1353 & $20.63 \%$ \\
More than $\$ 100,000$ but less than $\$ 250,000$ & 1041 & $15.87 \%$ \\
Less than $\$ 100,000$ & 161 & $2.46 \%$ \\
Total & 6558 & $100.00 \%$ \\
\hline Panel B: Number of Bids By Company & & \\
\hline & Number & of \\
Number of Bids Submitted & Companies & Percentage \\
\hline More than 100 & 19 & $5.18 \%$ \\
More than 50 but less than 100 & 16 & $4.36 \%$ \\
More than (or equal to) 20 but less than 50 & 37 & $10.08 \%$ \\
More than (or equal to) 10 but less than 20 & 44 & $11.99 \%$ \\
More than (or equal to) 5 but less than 10 & 62 & $16.89 \%$ \\
Less than 5 & 189 & $51.50 \%$ \\
Total & 367 & $100.00 \%$ \\
\hline
\end{tabular}

As mentioned previously, we use the median of all companies' bidding values on a project as the benchmark, as the median represents a consensus of the project value. The use of median as the benchmark has been used in several other studies and is supported by our data. For each bid on each project, we calculate the percent difference from the median of all bids submitted on that project. Figure 1 shows that the distribution of bids amounts in terms of the percent difference from the median for all projects follows a bell-shaped fashion. Based on our data, $64.23 \%$ of bids amounts are within $10 \%$ difference (both positive and negative percent differences) from the median, $85.65 \%$ of bids amounts are within $20 \%$ difference from the median, and $92.66 \%$ of bids amounts are within $30 \%$ difference from median for all projects and all companies considered in the study. Therefore, our use of the percent deviation from the median of all bids on a project to measure cost estimation errors seems warranted.

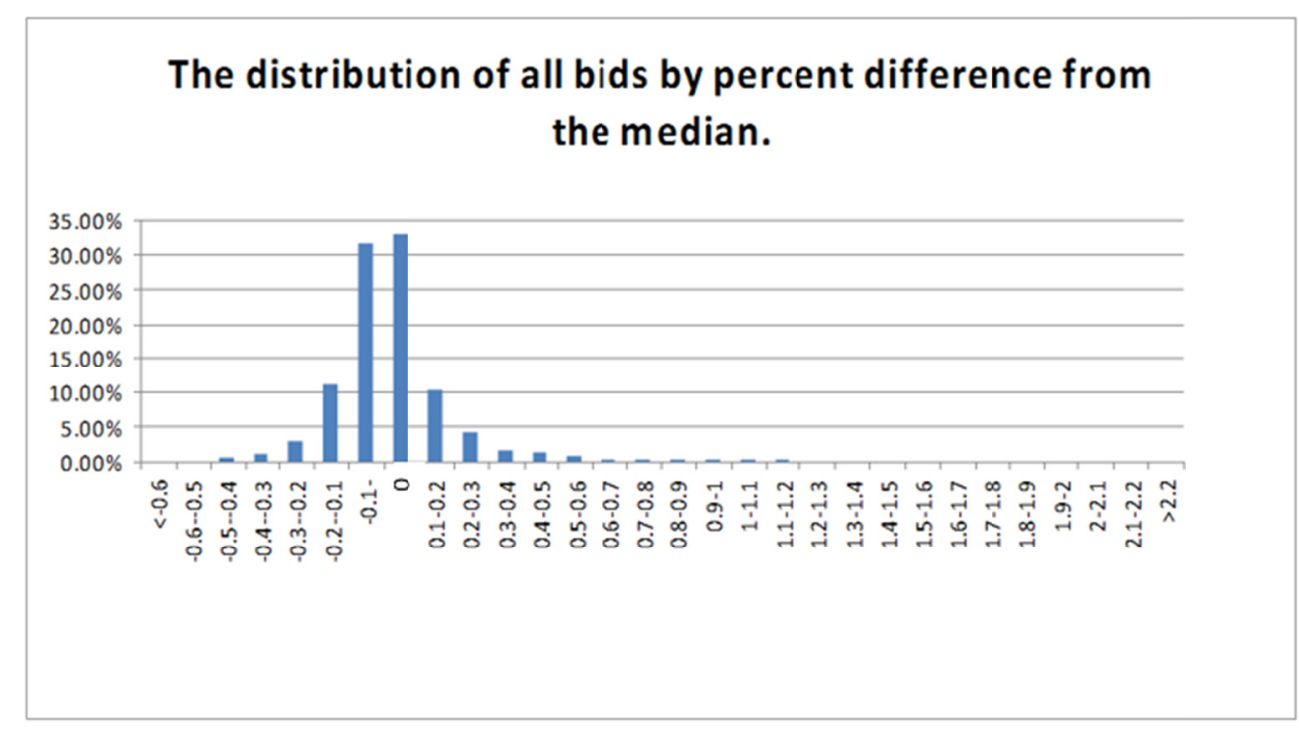

Figure 1. Distribution of all bids by percent difference from median bid on each project

\subsection{Test of Hypotheses}

To test our hypotheses, we only consider those companies that submitted bids on ten or more projects as it is difficult to draw any conclusion from these occasional behaviors (e.g., submitting less than ten bids). Hypothesis 1 (H1) predicts that a company that can better estimate its costs (i.e., a tighter bid distribution around consensus 
values like median) will tend to submit lower bids on average. We use a regression analysis to test this hypothesis where the independent variable is cost estimation accuracy, measured as standard deviation of bid's percent difference from the median. That is, for each company, we calculate its bid's percent difference from the median for each project the company bids on, and then we calculate the standard deviation of these percent differences. The dependent variable is the average of all bids amounts a particular company submits. As shown in Table 2, we find that $\mathrm{H} 1$ is strongly supported (t-value $=10.243$, p-value $=0.00$ ). From Figure 2, we know that the smaller of the standard deviation for a company (i.e., the tighter of a bid distribution around the median), the lower bids on average the company bids. In other words, when companies have more accurate cost estimates, they have less of a need to pad their markup due to estimate uncertainties.

Table 2. Bid size as a function of cost estimation accuracy* for each company (test for H1)

\begin{tabular}{ll}
\hline Summary measures & \\
\hline Multiple R & 0.7636 \\
R-Square & 0.5831 \\
\hline
\end{tabular}

\begin{tabular}{|c|c|c|c|c|c|c|}
\hline \multicolumn{7}{|c|}{ Regression Result: } \\
\hline & Coefficient & Std. Error & t-value & p-value** & Lower limit & Upper limit \\
\hline Constant & -0.151 & 0.020 & -7.695 & 0.000 & -0.190 & -0.112 \\
\hline Accuracy & 1.238 & 0.121 & 10.243 & 0.000 & 0.998 & 1.479 \\
\hline
\end{tabular}

*: The cost estimation accuracy is measured as standard deviation of percent difference from the consensus value, median bid.

**: All p-values are two-tailed unless otherwise noted.

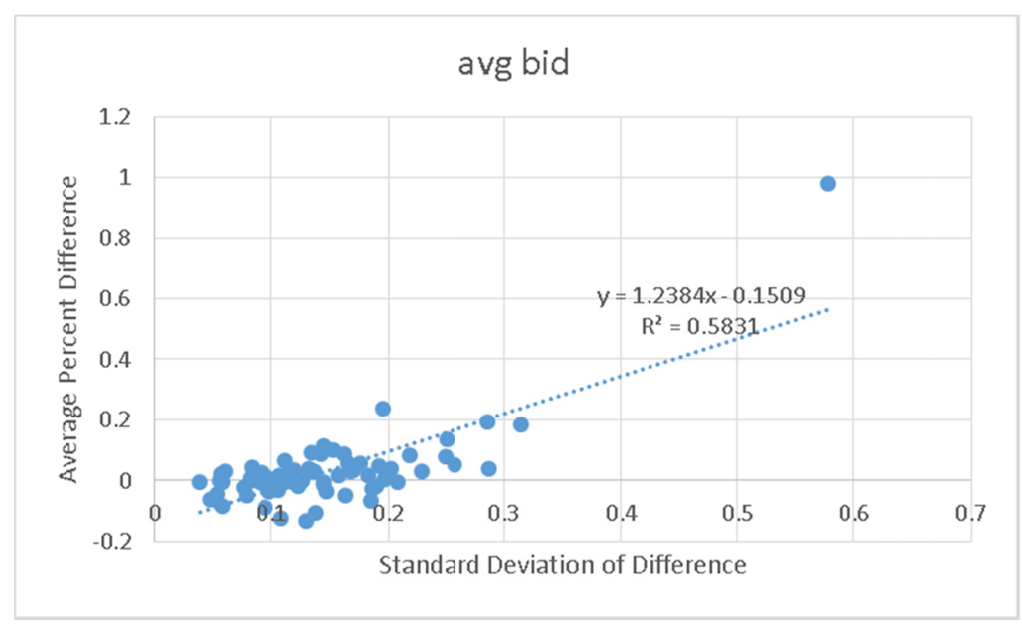

Figure 2. Average bid size as a function of cost estimation accuracy* by company (test for H1)

*: The cost estimation accuracy is measured as standard deviation of percent difference from the consensus value, median bid.

Hypothesis $2(\mathrm{H} 2)$ predicts that larger companies tend to have better cost estimation accuracy (i.e., tighter bid distributions around the consensus value). We use the total number of bids submitted by a company as a proxy for the size of the company, as we argue that generally a larger company has more resources (e.g., experts, facilities, etc.) and thus has the ability to bid on more projects, compared to a smaller company. We also expect larger companies to have more experience in bidding thus would be better able to estimate costs. Therefore, we expect that the more bids a company submits, the more likely the company's bids are closer to consensus values of projects (i.e., the tighter bid distribution around the median). Figure 3 Panel A shows that as companies submit more bids, there is a slightly increase in the standard deviation of percent difference from the median bid (i.e., a slightly further away from consensus values of projects), but this increase is not significant (Table 3 Panel A: $\mathrm{p}$-value $=0.5983$, two tailed). So, H2 is not supported. It may be that, while some companies with more experience and expertise indeed submit bids based on more accurate cost estimates many companies may just 
submit a large number of higher bids in the hope that they win a contract with as much profit as possible. This lack of support may also be due to our use of proxy for the size of a firm which may not accurately reflect company size (Note 2).

Table 3. Cost estimation accuracy* as a function of company size (test for $\mathrm{H} 2$ )

Panel A: Company size is measured by number of bids submitted by the company

\begin{tabular}{|c|c|c|c|c|c|c|}
\hline \multicolumn{7}{|c|}{ Summary measures } \\
\hline Multiple R & \multicolumn{2}{|c|}{0.0610} & & & & \\
\hline R-Square & \multicolumn{2}{|c|}{0.0037} & & & & \\
\hline \multicolumn{7}{|c|}{ Regression Result: } \\
\hline & Coefficient & Std. Error & t-value & $\mathrm{p}$-value** & Lower limit & Upper limit \\
\hline Constant & 0.1368 & 0.0138 & 9.8825 & 0.000 & 0.1092 & 0.1643 \\
\hline Num. of Bids & 0.0002 & 0.0003 & 0.5291 & 0.5983 & -0.0004 & 0.0008 \\
\hline
\end{tabular}

\section{Panel B: Company size is measured by average bid amount by the company}

\begin{tabular}{|c|c|c|c|c|c|c|}
\hline \multicolumn{7}{|c|}{ Summary measures } \\
\hline Multiple R & \multicolumn{2}{|c|}{0.0613} & & & & \\
\hline R-Square & \multicolumn{2}{|c|}{0.0038} & & & & \\
\hline \multicolumn{7}{|c|}{ Regression Result: } \\
\hline & Coefficient & Std. Error & t-value & p-value** & Lower limit & Upper limit \\
\hline Constant & 0.1477 & 0.0135 & 10.9376 & 0.000 & 0.1208 & 0.1746 \\
\hline Average Bid & 0.0000 & 0.0000 & -0.5318 & 0.5965 & 0.0000 & 0.0000 \\
\hline
\end{tabular}

*: The cost estimation accuracy is measured as standard deviation of percent difference from the consensus value, median bid.

**: All p-values are two-tailed unless otherwise noted.

\section{Panel A: Company size is measured by number of bids submitted by the company}

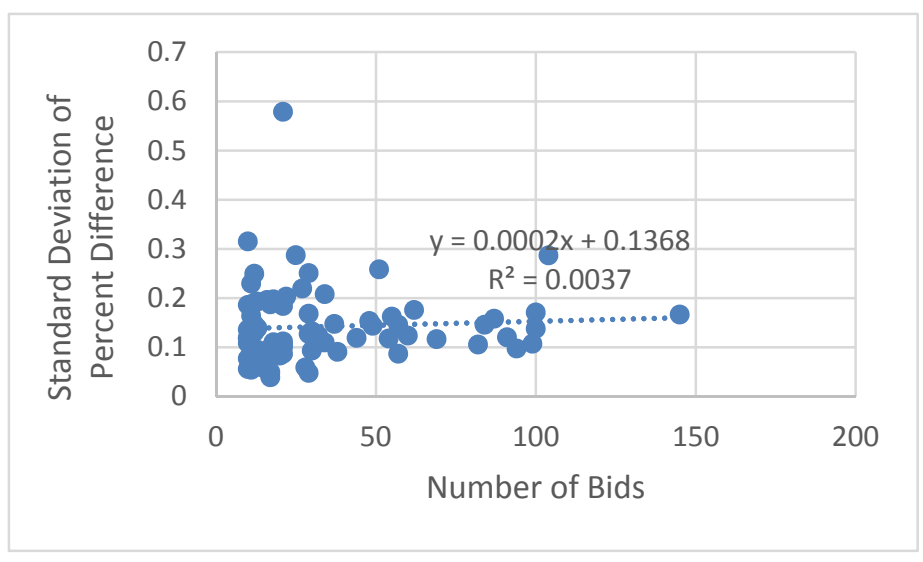




\section{Panel B: Company size is measured by average bid amount by the company}

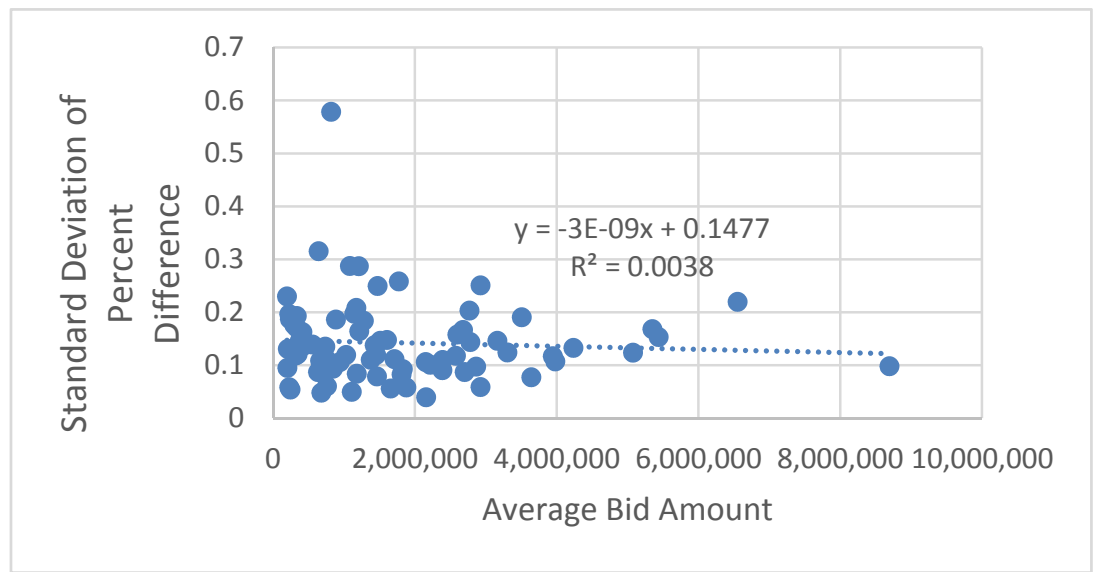

Figure 3. Cost estimation accuracy* as a function of company size (test for $\mathrm{H} 2$ )

*: The cost estimation accuracy is measured as standard deviation of percent difference from the consensus value, median bid.

Hypothesis 3 (H3) predicts that better cost estimates (i.e., a tighter bid distribution around the median) will lead to winning more projects than those companies with less accurate cost estimates. We show that a tighter bid distribution around consensus values (median) will lead to lower bids on average (supported by H1). Theoretically, if a company has a lower bid, it will have a higher probability to win the bid (since the lowest bid amount wins.) Our results suggest that $\mathrm{H} 3$ is marginally supported $(t=-1.64$, $\mathrm{p}$-value $=0.056$, one-tailed). As presented in Table 4 and Figure 4, when companies have a smaller standard deviation of percent difference from the median (i.e., a tighter distribution around consensus values which is indicative of better cost estimation), they tend to have a relatively higher probability of winning the bid.

Table 4. Percent of winning bids of bids submitted by each company as a function of cost estimation accuracy* for each project (test for H3)

\begin{tabular}{lllllll}
\hline $\begin{array}{l}\text { Summary measures } \\
\text { Multiple R }\end{array}$ & 0.1833 & & & & \\
R-Square & 0.0336 & & & & & \\
\hline Regression Result: & & & & & & \\
& Coefficient & Std. Error & t-value & p-value** & Lower limit & Upper limit \\
\hline Constant & 0.234 & 0.032 & 7.299 & 0.000 & 0.170 & 0.297 \\
Accuracy & -0.318 & 0.197 & -1.614 & 0.056 & -0.711 & 0.075 \\
\hline
\end{tabular}

*: The cost estimation accuracy is measured as standard deviation of percent difference from the consensus value, median bid.

**: One-tailed p-value is reported here because we predict a directional hypothesis. 


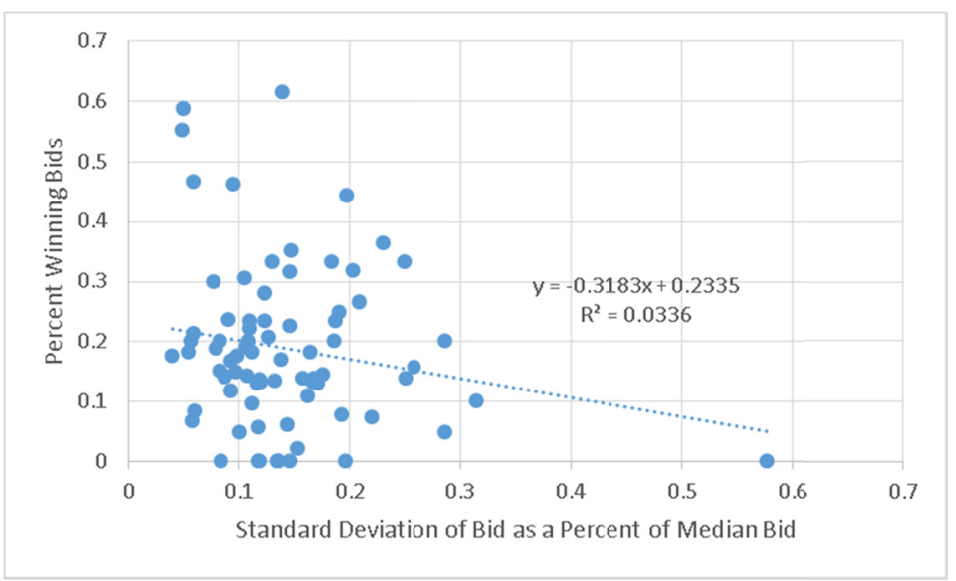

Figure 4. Percent of winning bids of bids submitted by each company as a function of cost estimation accuracy* (test for $\mathrm{H} 3$ )

*: The cost estimation accuracy is measured as standard deviation of percent difference from the consensus value, median bid.

\section{Conclusions}

Understanding whether cost estimation accuracy lead to improvements in decisions or overall competitiveness is an important issue in managerial accounting research. However, there is little empirical evidence that directly addresses this issue (Callahan \& Gabriel, 1998; Gupta \& King, 1997; Heitger, 2007). In this paper, we explore the advantages of better cost estimates in procurement auctions. Specifically, we examine the effect of cost estimation accuracy on a firms' ability to submit lower bid totals and their likelihood of winning more projects. Our results show that companies that have better cost estimates are in fact able to submit lower bids than companies with less accurate cost estimates. We also present evidence that companies that have more accurate cost estimates tend to win more bids than companies with less accurate estimation. These findings provide empirical support to the general assumption made in prior literature that more accurate cost estimation can lead to increased competitiveness (e.g., Babad \& Balachandran, 1993; Callahan \& Gabriel, 1998; Gupta \& King, 1999). However, we do not find any evidence that larger sized companies tend to more accurately estimate costs.

Our study is one of the few studies that empirically investigate the effect of more accurate cost estimation in the bidding process. Although our data comes from a single state and from a single industry, our results provide evidence that companies that have more accurate cost estimation do have advantages in the bidding process. Given that actual cost information for each project is not available, we could not directly test to see if better cost estimates result in higher profits. However, a company that has better cost estimates tend to submit lower bids amounts (H1) and tend to win more projects (H3). It is reasonable to suspect that this would directly translate into greater profitability. Due to the unavailability of the profit information from natural settings, there is very limited evidence in prior literature about the relationship between cost estimation accuracy and overall profits. However, for companies that have more accurate cost estimation, the tendency to submit lower bids amounts and to win more projects will eventually help the companies to achieve greater profit.

Future studies are encouraged to explore more areas about this relationship by using analytical modeling or experimental methodologies. Some interesting questions in this area include: what are the effects of better cost estimation accuracy on the likelihood of winning a bid actually being profitable (i.e., avoiding the winner's curse)? What are the impacts of different bidding strategies on profitability if bidder(s) have abilities to better estimate their costs? Would companies' markup (margin) strategies affect their profitability? How does the market situation (e.g., duopoly or oligopoly) play a role in this process? How can bid takers maximize their profits (or minimize their costs) in these dynamic bidding process? How does bidding process in a particular industry affect this process? In other words, do companies try to maximize their profits seeking some form of equilibrium or is it industry practice to use a standard markup? These questions are very important and should provide us a more comprehensive understanding of the effect of cost estimation accuracy in the bidding process.

\section{References}

Anderson, S. (1995). A framework for assessing cost management system changes: The case of activity based costing implementation at general motors, 1986-1993. Journal of Management Accounting Research, 7, 
$1-51$.

Babad, Y. M., \& Balachandran, B. V. (1993). Cost driver optimization activity-based costing. The Accounting Review, 68(3), 562-575.

Callahan, C. M., \& Gabriel, E. A. (1998). The differential impact of accurate product cost information in imperfectly competitive markets: A theoretical and empirical investigation. Contemporary Accounting Research 15(4), 419-455. http://dx.doi.org/10.1111/j.1911-3846.1998.tb00566.x

Christensen, J., \& Demski, J. S. (1997). Product costing in the presence of endogenous subcost functions. Review of Accounting Studies, 65-87. http://dx.doi.org/10.1023/A:1018325711417

Cooper, R., \& Kaplan, R. S. (1991). The design of cost management systems: Text, cases, and readings. Englewood Cliffs: Prentice Hall.

Datar, S., \& Gupta, M. (1994). Aggregation, Specification and Measurement Errors in Product Costing. The Accounting Review, 69(4), 567-591.

Davis, D. D., \& Holt, C. A. (1992). Experimental Economics. Princeton, NJ: Princeton University Press.

De Silva, D. G., Dunne, T., Kankanamge, A., \& Kosmopoulou, G. (2008). The impact of public information on bidding in highway procurement auctions. European Economic Review 52(1), 150-181. http://dx.doi.org/10.1016/j.euroecorev.2007.07.003

Foster, G., \& Swenson, D. W. (1997). Measuring the success of activity-based cost management and its determinants. Journal of Management Accounting Research, 9, 109-141.

Gordon, L. A., Cooper, R., Falk, H., \& Miller, D. (1981). The Pricing Decision National Association of Accountants.

Govindarajan, V., \& Anthony, R. (1983). How firms use cost data in pricing decisions. Management Accounting, 30-36.

Gupta, M., \& King, R. (1997). An experimental investigation of the effect of cost information and feedback on product cost decisions. Contemporary Accounting Research, 14(1), 101-127. http://dx.doi.org/10.1111/j.1911-3846.1997.tb00521.x

Heitger, D. L. (2007). Estimating activity costs: How the provision of accurate historical activity data from a biased cost system can improve individuals' cost estimation accuracy. Behavioral Research in Accounting, 19, 133-159. http://dx.doi.org/10.2308/bria.2007.19.1.133

Ittner, C., Lanen, W., \& Larcker, D. (2002). The association between activity-based costing and manufacturing performance. Journal of Accounting Research, 40(3), 711-726. http://dx.doi.org/10.1111/1475-679X.00068

Kaplan, R. S., \& Cooper, R. (1998). Cost and Effect: Using Integrated Cost Systems to Drive Profitability and Performance. Boston, MA: Harvard Business School Press.

Kaplan, R. S., \& Norton, D. (2001). The Strategy-Focused Organization: How Balanced Scorecard Companies Thrive in the New Business Environment. Boston, MA: Harvard Business School Press.

Swenson, D. (1995). The benefits of activity-based cost management to the manufacturing industry. Journal of Management Accounting Research, 7, 167-180.

\section{Notes}

Note 1 . The reverse auction is when the bidder with lowest (not the highest) bid wins the contract.

Note 2. Given the limitation of our dataset, we can only use number of bids as a proxy for company size, or use another proxy: the average dollar amount of the bids submitted by a company. But using the average dollar amount of the bids may limit our study in that smaller firms can only bid on small projects whereas larger companies can bid on large and small projects. Using the second proxy, we find consistent results (Panel Bs of Figure 3 and Table 3). Future studies may examine other proxies upon data availability. 


\section{Copyrights}

Copyright for this article is retained by the author(s), with first publication rights granted to the journal.

This is an open-access article distributed under the terms and conditions of the Creative Commons Attribution license (http://creativecommons.org/licenses/by/3.0/). 